\title{
Effect of basic fibroblast growth factor and cytochrome $c$ peroxidase combination in transgenic mice corneal epithelial healing process after excimer laser photoablation
}

\author{
This article was published in the following Dove Press journal: \\ Clinical Ophthalmology \\ 15 February 2011 \\ Number of times this article has been viewed
}

\author{
Sergio Zaccaria Scalinci' \\ Lucia Scorolli' \\ Alessandro Meduri² \\ Pier Luigi Grenga ${ }^{3}$ \\ Giulia Corradetti ${ }^{\prime}$ \\ Cristian Metrangolo' \\ 'Low Vision Center - University \\ of Bologna, Bologna, Italy; \\ ${ }^{2}$ Department of Surgical Specialities, \\ Ophthalmology Clinic, University of \\ Messina, Messina, Italy; ${ }^{3}$ Department \\ of Ophthalmology, University of Rome \\ "La Sapienza”, Rome, Italy
}

Purpose: To evaluate the role of prepared basic fibroblast growth factor (bFGF) and cytochrome $c$ peroxidase (CCP) combination eyedrops in corneal epithelial healing of transgenic mice (B6(A)-Rpe ${ }^{\text {rd12/J }}$ ) after excimer laser photoablation.

Materials and methods: In this prospective study, 216 eyes of 108 mice underwent bilateral photorefractive keratectomy. We considered 4 groups: A, B, C, and D. Group A received standard topical postoperative therapy with tobramycin, diclofenac, and dexamethasone eyedrops plus $\mathrm{CCP}$ at 3 drops per day for a week or until corneal re-epithelialization was achieved. Group B received standard topical postoperative therapy plus bFGF eyedrops and phosphate-buffered saline (PBS) 3 drops per day for a week or until corneal re-epithelialization was complete. In group $\mathrm{C}, 1$ eye received standard topical postoperative therapy plus CCP eyedrops, bFGF eyedrops, and PBS 3 drops per day for a week or until corneal re-epithelialization was complete. Control eyes (group D) received a standard topical postoperative therapy plus placebo eyedrops. Mice were followed-up for a week from the day after the surgery to evaluate the rate of corneal re-epithelialization.

Results: Data were analyzed by ANOVA using the XLSTAT 2010 software. Eyes in group $\mathrm{A}, \mathrm{B}$, and $\mathrm{C}$ healed completely before the fifth postoperative day, achieving, respectively, a re-epithelialization time of 92 hours $\pm 10 \mathrm{SD}, 90$ hours \pm 12 SD, and 86 hours \pm 12 SD. Group $\mathrm{D}$ had a re-epithelialization time of 121 hours $\pm 8 \mathrm{SD}(P<0.05)$. No side effects or toxic effects were documented.

Conclusions: Results suggest that re-epithelialization after phototherapeutic keratectomy can benefit from topical therapy with CCP/bFGF combination eyedrops. Further clinical studies are needed to evaluate the long-term effectiveness of these eyedrops to prevent corneal haze.

Keywords: cytochrome $c$ peroxidase, bFGF, corneal wound healing, excimer laser photoablation, transgenic mice, refractive surgery

\section{Introduction}

Photorefractive keratectomy (PRK) is the application of energy in the ultraviolet range (UV) (193 nm wavelength), generated by an argon-fluoride excimer laser to the anterior corneal stroma to reshape its curvature and correct a refractive error (myopia, astigmatism and, more recently, hypermetropia). Phototherapeutic keratectomy (PTK) is the same application of energy but used to reshape anterior corneal stroma without correcting a refractive error. The physical process of remodeling the corneal stroma by UV high-energy photons is called photoablation. Complications of PRK include under-correction, over-correction, and induced astigmatism, which may be caused
Correspondence: Sergio Zaccaria Scalinci Via Massarenti 9, 40I00 Bologna, Italy

Tel +3905I6364595

Mob +3933357II 228

Email szscalinci@yahoo.it 
by inadequate centralization or focusing during surgery. In fact, the success of PRK depends on uneventful corneal re-epithelialization and healing without postoperative complications such as infection, keratitis, or corneal haze.

All side effects of PRK are direct or indirect consequences of corneal epithelial defect and ablation of the anterior stroma produced by the laser action. After PRK the cornea becomes more susceptible to several pathologic agents (chemical, physical, biological) with the possible appearance of infective or inflammatory events, ${ }^{1}$ because of corneal de-epithelialization, Bowman's membrane destruction, and the exposure of the stroma, induced by photoablation. The cornea does not heal immediately but is covered by a discontinuous pseudomembrane, which is not enough to protect the underlying stroma. The release of cytokines, neuropeptides, and chemokines involved in the woundhealing cascade contribute to a vicious cycle of phlogosis and to the onset of corneal pain. ${ }^{2}$ During the 24 to 48 hours after refractive surgery, most patients complain of painful corneal symptoms of various intensity because of the exposure of the damaged nerve endings. ${ }^{3}$

Another undesirable complication of superficial laser photoablation, as with PTK, is the development of corneal haze, with a frequency of $2.5 \%$ to $5 \% .{ }^{4}$ These opacities appear to be a consequence of the destruction of Bowman's membrane and the repair and replacement of stromal tissue post-PRK. Equilibrium of these factors in corneal wound healing is the main requirement to maintain corneal transparency. This equilibrium can be compromised by the acute injuries (chemical, inflammatory and infective) that may occur during postoperatively. ${ }^{5-7}$

According to a previous study by Esquenazi, after excimer photoablation laser-assisted sub-epithelial keratectomy (LASEK)-treated eyes showed less keratocyte apoptosis, myofibroblast transformation, and upregulation in the synthesis of chondroitin sulfate than PRK-treated eyes. These differences may account for better visual acuity and less stromal haze in higher corrections in LASEK-treated eyes. ${ }^{8}$

Oxygen free radical-induced tissue damage following PRK is well documented. ${ }^{9-17}$

This study was performed to investigate the role of cytochrome $c$ peroxidase (CCP) and basic fibroblast growth factor (bFGF) combination on the rate of corneal epithelial healing after PTK in transgenic mice. We decided to use these mice for our study because they did not present either genetic alterations in the cornea or corneal wound healing defects and presented a homogeneous cytology, structure, and corneal metabolism.

\section{Cytochrome c peroxidase}

First described in 1940, ${ }^{18} \mathrm{CCP}$ is an enzyme located between the external and internal mitochondrial membrane of the yeast Saccharomyces cerevisiae. At this site, it catalyzes the oxidative reaction of ferrocytochrome $c$ in the presence of hydrogen peroxide: $\mathrm{H}_{2} \mathrm{O}_{2}+2$ ferrocytochrome $c+2 \mathrm{H}^{+} \rightarrow 2$ ferrocytochrome $c+2 \mathrm{H}_{2} \mathrm{O}$. Several studies have shown that this enzyme is part of the anti-oxidation defense system that prevents intracellular accumulation of peroxide. ${ }^{18-21}$

CCP is a mitochondrial antioxidant that catalyzes the degradation of hydrogen peroxide $\left(\mathrm{H}_{2} \mathrm{O}_{2}\right){ }^{22}$ It has a high affinity for 2 substrates: $\mathrm{H}_{2} \mathrm{O}_{2}\left(\mathrm{Km} 4.5 \times 10^{-6}\right)$ and ferrocytochrome $c\left(\mathrm{Km} 10^{-5}\right){ }^{20}$

The activity of CCP is comparable to glutathione peroxidase activity in mammals. ${ }^{9}$ Glutathione peroxidase is the major component of the defense system against oxidative damage. It is predominantly present in corneal epithelium and endothelium. A significant decrease in glutathione peroxidase activity and concentration after mechanical epithelial removal has been reported; photoablation of the stroma decreases glutathione peroxidase activity more than epithelial scraping. ${ }^{23}$

$\mathrm{H}_{2} \mathrm{O}_{2}$ is physiologically present with a concentration from 20 to $50 \mu \mathrm{M}$ in corneal tissues. After PRK, the production of free radicals is even greater. ${ }^{23}$ Local inflammatory responses following excimer laser photoablation include infiltration of the corneal stroma by polymorphonuclear cells and production of inflammatory mediators such as prostaglandin $\mathrm{E}_{2}$ and leukotriene B4. ${ }^{10}$ Ultraviolet radiation, polymorphonuclear cells infiltration, and thermal increase are the probable sources of reactive oxygen species after PRK. These degrade corneal collagen and proteoglycans and induce an aggressive wound-healing response. ${ }^{10}$ The disequilibrium between the concentration of the free-radical scavengers and oxygen radicals produces inappropriate corneal wound healing, which is responsible for corneal haze and refractive regression.

\section{Basic fibroblast growth factor}

First described in $1978,{ }^{18}$ bFGF is a member of the FGF family. bFGF has been show to have mitogenic, chemotactic, and angiogenic activity, promoting cell growth, differentiation, and motility. ${ }^{19,20} \mathrm{bFGF}$ is found in almost all tissues of mesodermal and neuroectodermal origin and also in tumors derived from these tissues. bFGF does not have a consensus signal sequence, ${ }^{21}$ and thus the mechanism of its release is not well understood. One line of thinking holds that bFGF may be released during cell injury. Many cells express bFGF only transiently and store it in a biologically inactive form..$^{22-26}$ 
bFGF is a 288-residue protein with 12 antiparallel beta sheets.

FGF receptors are encoded by a gene family consisting of at least 4 receptor tyrosine kinases that transduce important signals in a variety of developmental and physiological processes related to cell growth and differentiation, they are expressed on human bFGF-sensitive cells. Many different receptor phenotypes expressed in various cell types suggest a multifunctional role of bFGF: it stimulates the growth of fibroblasts, myoblasts, osteoblasts, neuronal cells, endothelial cells, keratinocytes, chondrocytes, and many other cell types. ${ }^{27-31}$

Production of growth factors by corneal cells and their presence in the tear fluid and aqueous humor is essential for maintenance and renewal of normal tissue in the anterior eye and the prevention of undesirable immune or angiogenic reactions. Growth factors also play a vital role in corneal wound healing, mediating the proliferation of epithelial and stromal tissue and affecting the remodeling of extracellular matrix. These functions depend on a complex interplay between growth factors of different types, the extracellular matrix, and regulatory mechanisms of the affected cells. ${ }^{32-36}$

The mechanism by which bFGF is released by the cells is not known. Levels of endogenous bFGF have been shown to increase at sites of injury, suggesting that its release and/or activation from intracellular sources and/or extracellular depots may be an integral part of the "rescue" effect. ${ }^{37-49}$

\section{Materials and methods}

The study included 216 eyes of 108 mice female B6(A)$\mathrm{Rpe}^{\mathrm{rd} 12 / \mathrm{J}}$ mice, weighing 30 to $40 \mathrm{~g}$. Mean age was 24 weeks $\pm 0.2 \mathrm{SD}$. We decided to use this particular strain of mice because they have proved to have a wound healing and phlogosis response similar to that in humans. Furthermore, the bFGF receptor of these mice present the same affinity of human bFGF.

All mice had bilateral simultaneous PTK.

The central corneal thickness of mice. determined by performing a pachymetry exam (Pacline 2000 - Ultrasound pachymeter; Optikon, Rome, Italy), ranged from $280 \mu \mathrm{m}$ to $300 \mu \mathrm{m}$. All mice suffering from ocular surface disease were excluded from the study. All animals were maintained and handled in accordance with standard laboratory conditions and fed with a commercial pellet diet.

The experiment was performed according to animal care regulations and after permission had been granted by the local animal research ethics committee.

During the preoperative visit the following preoperative examinations were performed under mixed anesthesia with ketamine and xylazine $(0.05 \%$ ketamine: $0.03 \mathrm{~mL}$ and $0.023 \%$ xylazine $0.01 \mathrm{~mL}$ ): slit-lamp biomicroscopy of the anterior segment (Haag-Streit 900, Berne, Switzerland); corneal pachymetry (Pacline 2000 - Ultrasound Pachymeter; Optikon).

Excimer laser photoablation was performed using an argon fluoride excimer laser (Mel-70, Zeiss, Germany) emitting at $193 \mathrm{~nm}$.

The corneal epithelium was removed by mechanical scraping using a hockey knife after the application of cotton tipped stick soaked in 70\% alcohol for 30 seconds followed by a balanced saline solution (BSS) wash. Photoablation was performed at the central cornea; an ablation rate of $1.5 \mu \mathrm{m}$ per pulse was calculated. The repetition rate was $5 \mathrm{~Hz}$, diameter of the ablation zone was $5.5 \mathrm{~mm}$, and ablation depth was 45 to $50 \mu \mathrm{m}$.

Postoperative therapy consisted of a topical antibiotic (tobramycin $3 \mathrm{mg}$ ) eyedrops and diclofenac was applied topically 4 times a day for 7 days. Corticosteroid (dexamethasone $1 \mathrm{mg}$ ) eyedrops were applied 3 times a day beginning from the seventh postoperative day.

For each mouse in group A, 1 eye was randomly assigned to the group that received standard therapy plus CCP; the fellow eye received standard therapy plus placebo (BSS 0.8\%) 3 times a day until the cornea had completely recovered. The drug (CCP), commercially available in Italy, was administered for 7 days postoperatively or until corneal re-epithelialization was complete at a dosage of 2 drops 3 times a day corresponding to 15,000 IU.

For each mouse of group B, 1 eye was randomly assigned to the group that received standard therapy plus bFGF; the fellow eye received standard therapy plus placebo (BSS $0.8 \%$ ) 3 times a day until the cornea had completely recovered. The drug was administered for 7 days postoperatively or until corneal re-epithelialization was complete at a dosage of $5 \mu \mathrm{g} / 10 \mu \mathrm{L}$ PBS 3 times a day.

For each mouse of group C, 1 eye was randomly assigned to the group that received standard therapy plus $\mathrm{CCP} / \mathrm{bFGF}$ combination; the fellow eye received standard therapy plus placebo (BSS 0.8\%) 3 times a day until the cornea had completely recovered. The drug was administered for 7 days after surgery or until corneal re-epithelialization was complete at a dosage of 2 drops 3 times a day corresponding to 15,000 IU of CCP and $5 \mu \mathrm{g} / 10 \mu \mathrm{L}$ PBS of bFGF 3 times a day.

Control eyes (group D) received a standard topical postoperative therapy plus placebo eyedrops. Mice were followed up for a week from the day after the surgery to evaluate the rate of corneal re-epithelialization.

Mice were monitored daily for 1 week starting 24 hours postoperatively to evaluate the corneal re-epithelialization rate. 
During the bio-microscopy examinations, video slit-lamp camera the corneal defects' horizontal diameter, stained by fluorescein, was measured on days 1 through to 7 or until complete re-epithelialization. The diameter of the epithelial defect was analyzed by a computer-image analyzer (Adobe 5 software) and then measured with computer pachimetry. The measurements of corneal wounds in the 2 groups were then compared. During follow-up slit-lamp bio-microscopy was performed to monitor corneal clarity.

The animals were sacrificed using sevoflurane inhalation anesthetic to determine a respiratory block after anesthesia with ketamine and xylazine $(0.05 \%$ ketamine: $0.03 \mathrm{~mL}$ and $0.023 \%$ xylazine $0.01 \mathrm{~mL}$ ) after 30 days after the excimer laser photoablation.

\section{Histology}

Mice eyes were fixed in 10\% buffered formalin for 24 hours, thereafter samples were dehydrated in graded series of ethanol, cleared in xylene, and embedded in paraffin. Sections were stained with hematoxylin and eosin. Thick sections of paraffin-embedded tissue $(5 \mu \mathrm{m})$ were cut and applied on $1 \%$ silane pre-coated slides. All incubations were performed in a humidified chamber. Sections were counterstained in Mayer's hematoxylin, dehydrated and mounted with DePeX Eukitt (Riedel de Haen, Seelze, Germany).

\section{Statistical analysis}

Data were evaluated by ANOVA using the XLSTAT 2010 software.

Continuous variables are expressed as mean \pm standard deviation (SD) and categorical variables are expressed as numbers and percentages.

Separate repeated measures ANOVA test models were used to assess differences in epithelial healing between groups A, B, C, and D (control group). We considered our results statistically significant at $P<0.05$.

Mauchly's sphericity test was used to examine the form of the error's covariance matrix; in case of violation of assumption, the Huynh-Feldt correction factor has been considered to obtain the adjusted $P$-values for each univariate $F$ test involving time-interval effect.

Bonferroni correction was used for multiple post hoc comparisons.

\section{Results}

Eyes treated with $\mathrm{CCP} / \mathrm{bFGF}$ combination (group C) showed a faster healing rate than eyes treated with standard therapy plus placebo (group D), eyes treated with CCP (group A), and eyes treated with bFGF (group B).

The mean defect diameter was as follows:

Day 1 postop: $4.41 \mathrm{~mm} \pm 0.12 \mathrm{SD}$ in $\mathrm{CCP}$ eyes (group A), $4.39 \mathrm{~mm} \pm 0.11 \mathrm{SD}$ in bFGF eyes (group B), $4.31 \mathrm{~mm} \pm 10 \mathrm{SD}$ in $\mathrm{CCP} / \mathrm{bFGF}$ combination eyes (group $\mathrm{C}$ ), and $5.01 \mathrm{~mm} \pm 0.11 \mathrm{SD}$ in standard therapy plus placebo eyes (group D);

Day 2 postop: $3.04 \mathrm{~mm} \pm 0.13 \mathrm{SD}$ in $\mathrm{CCP}$ eyes (group A), $3.03 \mathrm{~mm} \pm 0.10 \mathrm{SD}$ in $\mathrm{bFGF}$ eyes (group B), $3.00 \mathrm{~mm} \pm 10 \mathrm{SD}$ in $\mathrm{CCP} / \mathrm{bFGF}$ combination eyes (group C), and $3.97 \mathrm{~mm} \pm 0.12 \mathrm{SD}$ in standard therapy plus placebo eyes (group D);

Day 3 postop: $1.40 \mathrm{~mm} \pm 0.14 \mathrm{SD}$ in CCP eyes (group A), $1.39 \mathrm{~mm} \pm 0.13 \mathrm{SD}$ in $\mathrm{bFGF}$ eyes (B group), $1.33 \mathrm{~mm} \pm 14 \mathrm{SD}$ in $\mathrm{CCP} / \mathrm{bFGF}$ combination eyes (group C), and $3.08 \mathrm{~mm} \pm 0.11 \mathrm{SD}$ in standard therapy plus placebo eyes (group D).

By day 4 postop, most mice in group A (90\%), B (90\%), and $\mathrm{C}(90 \%)$ had healed completely; treated eyes that had not healed had mean residual defect diameters of $0.47 \mathrm{~mm} \pm 0.13 \mathrm{SD}, 0.39 \mathrm{~mm} \pm 0.14 \mathrm{SD}, 0.35 \mathrm{~mm} \pm 0.13 \mathrm{SD}$, and $1.96 \pm 0.14 \mathrm{~mm}$ in groups $\mathrm{A}, \mathrm{B}, \mathrm{C}$, and $\mathrm{D}$, respectively.

By day 5 postop, all eyes treated with $\mathrm{CCP}$, bFGF, $\mathrm{CCP} / \mathrm{bFGF}$ combination had completed the healing process; in standard therapy plus placebo eyes, the mean epithelial defect was $1.05 \mathrm{~mm} \pm 0.15 \mathrm{SD}$.

By day 6 postop, the mean epithelial defect was $0.30 \mathrm{~mm} \pm 0.13 \mathrm{SD}$ in group $\mathrm{D}$.

By day 7 postop, all eyes in group D had completed the re-epithelialization process (Figure 1).

Mean defect diameter values changed across time intervals (days) $(P<0.0001)$. Group $\mathrm{C}$ mice mean defect diameters differed from those of groups $\mathrm{A}, \mathrm{B}$, and $\mathrm{D}$ mice $(P<0.0001)$. The pattern of differences between mean defect diameter values for groups A, B, C, and D mice changed at each time interval $P<0.0001$ (Figure 1). Mean corneal re-epithelization time in group A eyes was 92 hours $\pm 10 \mathrm{SD}$, group B eyes 90 hours $\pm 12 \mathrm{SD}$, in group C eyes 86 hours $\pm 12 \mathrm{SD}$, and 121 hours $\pm 8 \mathrm{SD}$ in group $\mathrm{D}$ eyes. Corneal re-epithelization time differed significantly between group A, B, C, and D. The difference was greatest for group $\mathrm{C}$, indicating that the $\mathrm{bFGF} / \mathrm{CCP}$ combination is helpful in corneal re-epithelization after excimer laser photoablation in mice.

The histology showed that the epithelial cell layer was intact in all eyes of all four groups, with preservation of 


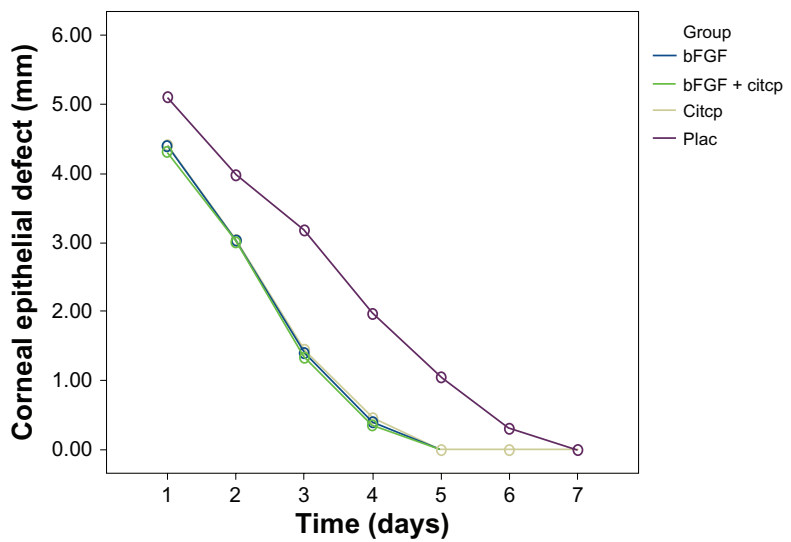

Figure I Average diameter of the defect of the corneal epithelium in eyes of group A (standard therapy plus cytochrome $c$ peroxidase $[C C P]$ ), group $B$ (standard therapy plus basic fibroblast growth factor [bFGF]), group C (standard therapy plus CCP/bFGF combination), and control group D (control; standard therapy plus placebo).

Notes: Standard therapy was postoperative therapy with tobramycin, diclofenac, and dexamethasone eyedrops.

Abbreviation: Citcp, cytochrome c peroxide.

cellular polarity, phenotype, and total layer thickness after 7 days. During the daily examinations no ocular or systemic adverse events were observed. No further effects of CCP and bFGF have been reported.

\section{Discussion}

Identification of factors that can aid corneal re-epithelization after epthelial injury, in this case induced by PRK, and avoid side effects related to corneal cicatrization can optimize surgical outcomes. Our hypothesis is that the $\mathrm{CCP} / \mathrm{bFGF}$ combination, by synergistic activity, accelerates the healing rate after PTK. CCP breaks the peroxidative chain reaction involving organic and fatty acid hydroperoxidase and prevents propagation of peroxide-dependent chain reactions that can lead to cell membrane lysis, and accelerate the healing rate. Moreover, $\mathrm{CCP}$ has a protective action against free-radical damage.

Also bFGF can reduce the harmful effects of reactive oxygen radicals after PTK and accelerates the healing rate. The therapeutic use of growth factors in corneal disease needs to be defined more clearly not only to accelerate and modulate cell proliferation in the corneal districts, but to avoid cicatrization disease and corneal dullness caused by inflammation of the stroma. On the cornea, bFGF induces epithelium cell proliferation, by modulating synthesis of extracellular matrix components and corneal basal membrane. Production of growth factors by corneal cells and their presence in the tear fluid and aqueous humor are essential for maintenance and renewal of normal tissue in the anterior eye and the prevention of undesirable immune or angiogenic reactions. Growth factors also play a vital role in corneal wound healing and affect the remodeling of the extracellular matrix. ${ }^{36}$ Moreover bFGF prevents haze increasing (transparency alteration activated by anomalous fibroblasts cell proliferation). Corneal damages usually cause an inflammation reaction and all phenomena correlated to phlogosis will occur. Growth factors are also released. Neovascularization of the cornea is a feared sequela to injuries and ulcers of the cornea, as well as to other types of inflammation. Neovascularization not only reduces vision, but can cause chronic irritation. We suggest that the $\mathrm{CCP} / \mathrm{bFGF}$ combination is primarily involved in the healing process of corneal epithelium where there is an immediate inflammatory response instead of stromal wound healing.

One study has suggested that the degree and extent of keratocytes apoptosis varies with the type of overlying epithelial injury (PRK or laser in situ keratomileusis) and is influenced by changes in surgical technique or pharmacologic therapy. ${ }^{30}$ This means that if rapid re-epithelialization occurs that preserves the epithelium corneal cytoarchitecture, the replacement of stroma with minimal cell apoptosis is guaranteed.

In our study the $\mathrm{CCP} / \mathrm{bFGF}$ combination was efficient in decreasing corneal re-epithelialization time after PTK without significant ocular or systemic adverse events, and this corneal re-epithelialization was faster than with only topical therapy with bFGF or CCP.

Moreover, the standard treatment contains a cocktail of dexamethasone, diclofenac, and trobramicin; it is well established that the potent long-acting steroid dexamethasone inhibits wound healing and inflammation, significantly increases intraocular pressure, and upregulates superoxide dismutase. Diclofenac, a very potent nonsteroidal antiinflammatory drug, also delays wound healing and inhibits inflammation by completely inhibiting corneal prostaglandin formation. Both drugs significantly change normal wound healing. We were surprised that adding more drugs to an already complex mixture changed the rate of wound healing: growth factors such as bFGF partially possibly reversed the negative action of the dexamethasone on wound healing.

In conclusion, topical therapy with the $\mathrm{CCP} / \mathrm{bFGF}$ combination is useful for reducing the harmful effects of reactive oxygen radicals after PTK and accelerates healing rate. Further investigations are required to confirm our results before clinical trials are begun.

\section{Disclosure}

The authors disclose no conflicts of interest. 


\section{References}

1. Paysse EA, Hamill MB, Koch DD, et al. Epithelial healing and ocular discomfort after photorefractive keratectomy in children. J Cataract Refract Surg. 2003;29:478-481.

2. Kuo IC. Corneal wound healing. Curr Opin Ophthalmol. 2004;15: 311-315.

3. Patel GM, Chuang AZ, Kiang E, et al. Epithelial healing rates with topical ciprofloxacin, ofloxacin and ofloxacin, with artificial tears after photorefractive keratectomy. J Cataract Refract Surg. 2000;26: 690-694.

4. Hersh PS, Stulting RD, Steinert RF, et al. Results of phase III excimer laser photorefractive keratectomy for myopia. The Summit PRK Study Group. Ophthalmology. 1997;104:1535-1553.

5. Kasetsuwan N, Wu FM, Hsieh F, et al. Effect of topical ascorbic acid on free radical tissue damage and inflammatory cell influx in the cornea after excimer laser corneal surgery. Arch Ophthalmol 1999; 117:649-652.

6. Kourenkov VV, Mytiagina ON, Kasparov AA, et al. Stimulating re-epithelialization after photo-refractive keratectomy. J Refract Surg. 1999;15:S234-S237.

7. Baiocchi S, Frezzotti P, Sforzi C, et al. Terapia farmacologia nella cheratectomia fotorefrattiva (PRK). In: Chirurgia Rifrattiva, Principi e Tecniche. Rapporto della Societa Ofttalmología Italiana. Fabiano Editore. 2000.

8. Esquenazi S, He J, Bazan NG, et al. Comparison of corneal wound-healing response in photorefractive keratectomy and laser-assisted sub-epithelial keratectomy. J Cataract Refract Surg. 2005;31(8):1632-1639.

9. Armstrong D, Santangelo G, Connole E. The distribution of peroxide regulation enzyme in the canine eye. Curr Eye Res. 1981;1: 225-242.

10. Hayashi S, Ishimoto $\mathrm{S}, \mathrm{Wu} \mathrm{GS}$, et al. Oxygen free radical damage in the cornea after excimer laser therapy. $\mathrm{Br} J$ Ophthalmol. 1997;81:141-144.

11. Shimmura S, Masumizu T, Nakai Y, et al. Excimer laser-induced hydroxy radical formation and keratocyte death in vitro. Invest Ophthalmol Vis Sci. 1999;40:1245-1249.

12. Bilgihan A, Bilgihan K, Yis Ö, et al. The effect of excimer laser keratectomy on corneal glutathione-related enzymes in rabbits. Free Radic Res. 2003;37:399-403.

13. Bilgihan K, Bilgihan A, Adiguzel U, et al. Keratocyte apoptosis and corneal antioxidant enzyme activities after refractive corneal surgery. Eye. 2002;16:63-68.

14. Yis Ö, Bilgihan A, Bilgihan K, et al. The effect of excimer laser keratectomy on corneal glutathione peroxidase activities and aqueous humor selenium levels in rabbits. Graefes Arch Clin Exp Ophthalmol. 2002;240:499-502.

15. Bilgihan A, Bilgihan K, Yis Ö, et al. Effects of topical vitamin E on corneal superoxide dismutase, glutathione peroxidase activities and polymorphonuclear leucocyte infiltration after photorefractive keratectomy. Acta Ophthalmol Scand. 2003;81:177-180.

16. Brancato R, Schiavone N, Siano S, et al. Prevention of corneal keratocyte apoptosis after argon fluoride excimer laser irradiation with the free radical scavenger ubiquinone Q10. Eur J Ophthalmol. 2000; 10:32-38.

17. Bilgihan K, Ozdek S, Ozogul C, et al. Topical vitamin E and hydrocortisone acetate treatment after photorefractive keratectomy. Eye. 2000;14:231-237.

18. Federici G, Bertoncelli M, Drago F. Un nuovo enzima detossificante, il citocromo c perossidasi, per il trattamento delle lesioni corneali e di altre patologie oculari. In: Drago F, editor. Farmacologia Oculare; Attualità e Prospettive; Cappelli Editore; Bologna, 1988:445-450.

19. Yonetani T, Ray GS. Studies on cytochrome c peroxidase. III. Kinetics of the peroxidatic oxidation of ferrocytochrome c catalyzed by cytochrome c peroxidase. J Biol Chem. 1966;241:700-706.

20. Finzel BC, Poulos TL, Kraut J. Crystal structure of yeast cytochrome c peroxidase refined at 1.7 - A resolution. J Biol Chem. 1984;259: $13027-13036$
21. Takio K, Yonetani T. Primary structure of yeast cytochrome c peroxidase. I. Chemical characterization of the polypeptide chain of typtic and chymotrptic peptides. Arch Biochem Biophys. 1980;203: 605-614.

22. Giles SS, Perfect JR, Cox GM. Cytochrome c peroxidase contributes to the antioxidant defense of Cryptococcus neoformans. Fungal Genet Biol. 2005;42:20-29.

23. Wilson SE, Netto M, Ambrósio RJ. Corneal cells: chatty in development, homeostasis, wound healing, and disease. Am J Ophthalmol. 2003;136:530-536.

24. Gospodarovicz D, Neufeld G, Scheigerer L. FGF structural and biological properties. J Cell Phisiol. 1987;5:15-26.

25. McFarlane S, McNeil L, Holt. FGF signaling and target recognition in the developing Xenopus visual system. Neuron. 1995;15: 1017-1028.

26. Unsickler K, Groethe C, Otto D, et al. Basic fibroblast growth factor in neurons and its putative functions. Annals of the New York Academy of Science. 1991;68:300-305.

27. Abraham JA, Mergia A, Whang L, et al. Nucleotide sequence of a bovine clone encoding the angiogenic protein, basic fibroblast growth factor. Science. 1986;233:545-548.

28. Guillonneau X, Regnier-Ricard F, Dupuis C, et al. FGF2-stimulated release of endogenous FGF-1 is associated with reduced apoptosis in retinal pigmented epithelial cell. Exp Cell Res. 1997;233: 198-206.

29. Zhu X, Komiya H, Chirino A, et al. Three-dimensional structure of acidic and basic fibroblast growth factors. Science. 1991;251:90-94.

30. Seddon A, Decker M, Muller T, et al. Structure /activity relationships in basic FGF. Annals of New York Academy of Science. 1991;68: 98-108.

31. Moscatelli D. High and low affinity binding sites for bFGF on cultured cells. Absence of a role for the low affinity binding in the simulation of plasminogen activator production by bovine capillary endothelial cells. J Cell Phyisiol. 1987;131:123-130.

32. Assouline M, Morton K, Hutchinson C, et al. In vivo binding of topical bFGF on rabbit corneal wound. Growth factors. 1989;1:251-261.

33. Johnson DE. Diverse forms of a receptor for acidic and basic fibroblast growth factors. Molecular Cellular Biology. 1990;10:4728-4736.

34. Partanen J. Diverse receptors of fibroblast growth factors. Progress in Growth Factor Research. 1992;4:69-83.

35. Lindner V, Reidy MA. Proliferation of smooth muscle cells after vascular injury is inhibited by an antibody against basic fibroblast growth factor. Proceedings of the National Academy of Sciences. 1991;88: 3739-3743.

36. Lindner V. Role of basic fibroblast growth factor in vascular lesion formation. Circulation Research. 1991;68:106-113.

37. Mayahara $H$. In vivo stimulation of endosteal bone formation by basib fibroblast growth factor in rats. Growth Factors. 1993;9:73-80.

38. Faktorovich EG, Steinberg RH, Yasumura D, et al. Photoreceptor degeneration in inherited retinal dystrophy delayed by basic fibroblast growth factor. Nature. 1990;347:83-86.

39. Faktorovich EG, Steinberg RH, Yasumura D, et al. Basic fibroblast growth factor and local injury protect photoreceptors from light damage in the rat. J Neurosci. 1992;12:3554-3567.

40. Lin N, Fan W, Sheedlo HJ, et al. Basic fibroblast growth factor treatment delays age-related photoreceptor degeneration in Fischer 344 rats. Exp Eye Res. 1997;64:239-248.

41. Karsan A, Yee E, Poirier GG, et al. Fibroblast growth factor-2 inhibits endothelial cell apoptosis by Bcl-2 dependent and independent mechanism. Am J Pathol. 1997;151:1775-1784.

42. Klenkler B, Sheardown H. Growth factors in the anterior segment: role in tissue maintenance, wound healing and ocular pathology. Experimental Eye Research. 2004;79:677-688.

43. Eckenstein FP, Shipley GD, Nishi R. Acidic and basic fibroblast growth factors in the nervous system: distribution and differential alteration of levels after injury of central versus peripheral nerve. $J$ Neurosci. $1991 ; 11: 412-419$ 
44. Finklestein SP, Apostolides PJ, Caday CG, et al. Increased basic fibroblast growth factor (bFGF) immunoreactivity at the site of focal brain wounds. Brain Res. 1988;460:253-259.

45. Frautschy SA, Walicke PA, Baird A. Localization of basic fibroblast growth factor and its mRNA after CNS injury. Brain Res. 1991;553: 291-299.

46. Gomez-Pinilla F, Cotman CW. Transient lesion-induced increase of basic fibroblast growth factor and its receptor in layer VIb (subplate cells) of the adult rat cerebral cortex. Neuroscience. 1992;49:771-780.
47. Kostyk SK, D'Amore PA, Herman IM. Optic nerve injury alters basic fibroblast growth factor localization in the retina and optic tract. J Neurosci. 1994;14:1441-1449.

48. Logan A, Frautschy SA, Baird A. Basic fibroblast growth factor and central nervous system injury. Ann NY Acad Sci. 1991;638:474-476.

\section{Publish your work in this journal}

Clinical Ophthalmology is an international, peer-reviewed journal covering all subspecialties within ophthalmology. Key topics include: Optometry; Visual science; Pharmacology and drug therapy in eye diseases; Basic Sciences; Primary and Secondary eye care; Patient Safety and Quality of Care Improvements. This journal is indexed on PubMed

Submit your manuscript here: http://www.dovepress.com/clinical-ophthalmology-journal

\section{Dovepress}

Central and CAS, and is the official journal of The Society of Clinical Ophthalmology (SCO). The manuscript management system is completely online and includes a very quick and fair peer-review system, which is all easy to use. Visit http://www.dovepress.com/testimonials. php to read real quotes from published authors. 